RESEARCHPAPER

\title{
In vitro total antioxidant activity and nitric oxide scavenging of Anogeissus latifolia
}

\author{
AAKANKSHA, RAMESHWAR GROACH AND NARENDER SINGH \\ Department of Botany, Kurukshetra University, KURUKSHETRA (HARYANA) INDIA \\ Email : rameshwar.groach@kuk.ac.in
}

Article Info : Received : 10.06.2017; Revised : 25.08.2017; Accepted : 25.09.2017

Anogeissus latifolia (Roxb.Ex DC.) Wall.exGuill. \&Perr. (Combretaceae) commonly known as bakli, dhau, dhawa or axle wood is a moderate sized tree characteristic of dry deciduous forests flourishing mainly in India. It is used in traditional systems of medicine to enhance the immune system and in the treatment of diabetes mellitus, diarrhoea, dysuria, cough, colic, snakebite, digestive ailments, skin and cardiovascular diseases. In this study, methanol and water extracts were prepared from powdered bark and leaf of A. latifolia. The extracts were studied for nitric oxide scavenging and total antioxidant activities determined by spectrophotometric technique. The results of this study show that the methanol and water extracts of A. latifolia can be used as an easily accessible source of natural antioxidants.

Key words : A. latifolia, Nitric oxide scavenging, Total antioxidant

How to cite this paper : Aakanksha, Groach, Rameshwar and Singh, Narender (2017). In vitro total antioxidant activity and nitric oxide scavenging of Anogeissus latifolia. Asian J. Bio. Sci., 12 (2) : 254-258.DOI : 10.15740/HAS/AJBS/12.2/254-258. 